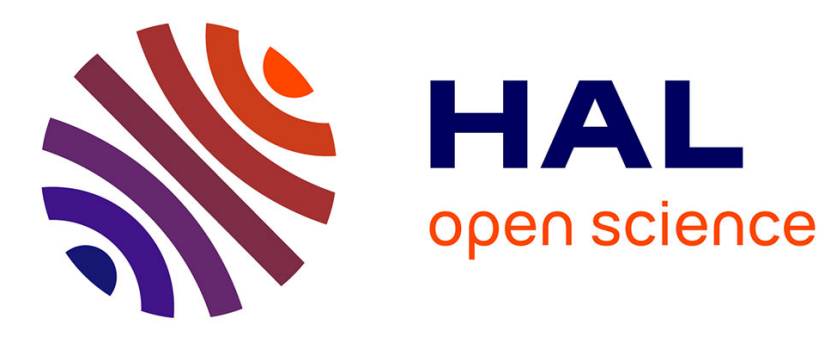

\title{
Prevalence of anxiety and depression among diabetic African patients in Guinea: Association with HbA1c levels.
}

Alioune Camara, Naby Moussa Baldé, Sostanie T. Enoru, J. S. Bangoura, Eugène Sobngwi, Fabrice Bonnet

\section{To cite this version:}

Alioune Camara, Naby Moussa Baldé, Sostanie T. Enoru, J. S. Bangoura, Eugène Sobngwi, et al.. Prevalence of anxiety and depression among diabetic African patients in Guinea: Association with HbA1c levels.. Diabetes \& Metabolism, 2015, 41 (1), pp.62-68. 10.1016/j.diabet.2014.04.007 . hal01068861

\section{HAL Id: hal-01068861 https://hal-univ-rennes1.archives-ouvertes.fr/hal-01068861}

Submitted on 26 Sep 2014

HAL is a multi-disciplinary open access archive for the deposit and dissemination of scientific research documents, whether they are published or not. The documents may come from teaching and research institutions in France or abroad, or from public or private research centers.
L'archive ouverte pluridisciplinaire HAL, est destinée au dépôt et à la diffusion de documents scientifiques de niveau recherche, publiés ou non, émanant des établissements d'enseignement et de recherche français ou étrangers, des laboratoires publics ou privés. 


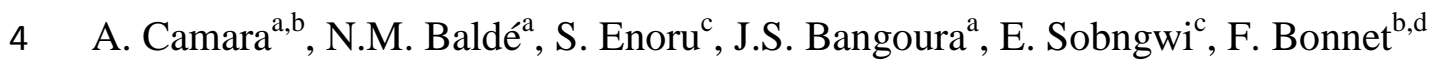

5

6

7

8

Correspondance to:

CAMARA Alioune

INSERM, CIC 0203, CHU de Rennes,

Hôpital de Pontchaillou,

Pavillon Clemenceau, 2 rue Henri Le Guilloux, 35033 Rennes Cedex 9, France

Tel: +33223234713 (secrétariat) or +33 608850590 (Portable) aliounec@gmail.com 


\section{Abstract}

2

3 Aim.- The prevalence and risk factors associated with symptoms of anxiety and depression 4 were determined in African people with diabetes.

5 Methods.- This cross-sectional study involving 491 out-patients with type 2 diabetes (T2D)

6 recruited from four diabetes clinics (Conakry, Labé, Boké, Kankan) in Guinea was carried

7 out. The Hospital Anxiety and Depression Scale was used to evaluate the symptoms of

8 anxiety and depression. Logistic regression analysis stratified by sex was performed to

9 identify the associated risk factors.

Key words: Anxiety, depression, type 2 diabetes, risk factors 
2 According to the World Health Organization, we are facing an epidemic of diabetes in developing countries. Currently, over $80 \%$ of people with diabetes live in low and middle income countries (LMICs) [1]. This clinical situation relates also to Guinea where the agestandardized prevalence of diabetes according the Guinean census was 6.5\% (95\% CI: 5.3$7.7 \%)[2]$.

A large body of evidence has highlighted that both anxiety and depression are more common in people with diabetes than in the general population $[3,4]$. Furthermore, it has been consistently shown that depression is associated with an increased risk of morbidity and mortality in people with diabetes $[3,4]$ and that depression may have a deleterious impact on adherence to glucose lowering treatments [5]. However, recent studies suggest that psychological disorders remain often undiagnosed and therefore not appropriately treated among people with diabetes [6,7]. This issue is particularly relevant in Africa where healthcare infrastructures have mainly focused on infectious diseases rather than on type 2 diabetes (T2D). Yet, the combination of depression and diabetes among the poor populations in LMICs might favor the development of diabetic complications and ultimately greater morbidity and mortality [8].

Epidemiological data on the characteristics of T2D patients who are most affected by anxiety/depression in LMICs remain sparse but are essential to implement public health programmes in these countries [8]. The goal of the present study is to assess the prevalence of both anxiety and depression in people with T2D in Guinea and to identify the factors associated. Furthermore, we examined whether the association between psychological distress and diabetes is affected by the level of glycaemic control in these people from a low-income country who have limited access to regular healthcare. 


\section{Materials and Methods}

\subsection{Study setting and design}

This cross-sectional multicentre study was conducted in four institutions in Guinea: the

Endocrinology, Diabetology and Metabolic Disease Unit of the University Teaching Hospital (UTH) of Conakry, and the Diabetes Unites of regional Hospitals at Boké, Kankan and Labé.

\subsection{Population}

Between August 2009 and October 2010, a study to improve access to glycated haemoglobin (HbA1c) in diabetic patients was carried out in Cameroon and Guinea. The study included patients aged $\geq 16$ years and having T2D for at least 12 months. They were contacted at the outpatient clinic of the four study sites and invited to participate in the study. Patients who had lost a family member (parent, brother, sister, husband, children) and/or lost their job in the month preceding the study were excluded from the study. In total, 491 patients with T2D were included in this study.

\subsection{Methods}

A semi-structured questionnaire and a standardized interview were completed for all patients. Data involving socioeconomic status (SES), history of diabetes and levels of anxiety and depression were collected.

\subsection{Socio-demographic profile}

The Socio-demographic data collected included age, sex, zone of residence (rural or urban), marital status (single or married) and unemployment status (yes or no). The level of education was divided into two classes (less than 7 years of school, at least 7 years of school). SES was assessed from unemployment status and level of education and dichotomized into low (lower education and unemployment) or high (higher education or/and employment).

\subsection{History of diabetes and clinical data}

Other information collected included type of glucose lowering treatment, duration of diabetes and previous measurement of $\mathrm{HbA} 1 \mathrm{c}$ (yes or no). HbA1c was classified into: $<7.0 \%$, 7.0 to $8.9 \%$ and $\geq 9.0 \%$.

The clinical data collected including current tobacco smoking (yes or no) and known hypertension (yes or no). Alcohol consumption during the previous month was self-reported. Body mass index (BMI) was calculated. 


\subsection{Level of Anxiety and depression:}

Symptoms of anxiety and depression were evaluated using the Hospital Anxiety and Depression Scale (HADS) [9]. The French version that we used had previously been validated, both in family medicine and in hospital settings [10]. The HADS measures levels of symptoms in the last week. There is a medium-to-strong correlation between the HADS score and other instruments used to measure anxiety and depression, including the Beck's Depression Inventory, Spielberger's State-Trait Anxiety Inventory, the Symptom Checklist 90 Scale, and the Montgomery-Asberg Depression Rating Scale [11]. The main characteristic of HADS is that items that could be attributed to physical illnesses, such as insomnia, fatigue, headaches, dizziness, sleep, and appetite disturbance, have been omitted to avoid falsepositive cases among individuals with somatic diseases. HADS has 14 questions: seven related to depression (HADS-D) and seven related to anxiety (HADS-A). Each question has four possible responses from zero (no symptoms) to three (maximum symptoms). The severity of the symptoms is determined by the total score obtained in each sub-scale (HADSA and HADS-D) and is classified as: 0-7 (normal), 8-10 (mild disorder) and 11-21 (marked disorder). HADS-D covers mainly anhedonia and loss of interest, which are core depressive symptoms, while HADS-A covers the core anxiety features of worry and tenseness.

\subsection{Ethical considerations:}

The ethics committee of the Ministry of public health of Guinea approved the study. Only patients who signed the informed consent form were included in the study.

\subsection{Statistical analysis:}

The prevalence of symptoms of anxiety and depression was determined using the HADS scale and classified as normal, mild, and marked disorder. For the logistic regression analysis, the HADS scores were dichotomized as normal (score 0 - 7) and presence of anxiety / depression (score 8 - 21), to include all possible cases of anxiety and depression as suggested by Zigmond [9]. Univariate logistic regression analyses evaluated the relationships between anxiety and depression and the associated factors, and results are presented as odd ratios (OR) and $95 \%$ confidence intervals. Interactions were tested with sex, and as there was a signification interaction for some variables, all results are presented stratified on sex. Variables with $\mathrm{p}$ values $<0.20$ in the univariate tests were selected as covariates for the multivariable models. A p value $<0.05$ was considered statistically significant. Analysis used SAS (version 9.3; SAS Institute, Cary, NC). 


\section{Results}

3.1 General patients' description

General characteristics of the 491 people with T2D included in this study are presented in Table 1. The majority was female (62.7\%), married (76.4\%), with a job $(54.2 \%)$ and high level of education (50.5\%). No patient was treating with antidepressant drugs. Mean age was $57.9 \pm 10.2$ years, and the men were older $(59.8 \pm 9.7)$ than the women $(56.7 \pm 10.3)$. Only $6.7 \%$ of the patients had a previous measurement of HbA1c. Out of all the study patients, $15.7 \%$ had a good glycaemic control (HbA1c <7.0\%), and 29.1\% ( $n=143)$ were being treated with insulin, with the remainder taking oral glucose-lowering drugs.

\subsection{Prevalence of anxiety and depression}

On the HADS, a mean score of $8.5 \pm 3.2$, with a median of 8 for anxiety was recorded. For depression, the mean score was $6.3 \pm 3.3$ with a median of 6 . Table 2 presents the prevalence of anxiety and depression as classified by the HADS according to gender. Symptoms of anxiety were present in $58.7 \%$ of patients while $34.4 \%$ had symptoms of depression. The prevalence of marked anxiety was $27.5 \%$ and was more common in women $(36.1 \%)$ when in men $(13.1 \%)$. Marked depression was present in $11.4 \%$ of the population, and again was more common in women (14.0\%) as compared to men (7.1\%). Of our 491 diabetic patients, 127 (25.9\%) had both anxiety and depression and neither anxiety nor depression was related to overweight/obese status.

\subsection{Factors associated with anxiety}

As shown in Table 3, anxiety in men was significantly associated with low SES [Odds ratio: 0.19 (95\% CI: 0.05 to 0.70 )], HbA1c 7-8.9\% [2.80 (1.13 to 6.93)] and $\mathrm{HbAlc} \geq 9.0 \%$ [2.61 (1.07 to 6.39)] in the multivariable model. In women, only residence in urban area [2.98 (1.81 to 4.89$)$ ] was associated with anxiety in the multivariable model.

\subsection{Factors associated with depression}

In a multivariate model (Table 4), depression in men was significantly associated with insulin therapy [2.28 (1.05 to 4.92)], and $\mathrm{HbA} 1 \mathrm{c} \geq 9.0 \%$ [3.85 (1.02 to 14.48)]. In women, age [1.03 (1.01 to 1.06)], residence in an urban area [2.13 (1.27 to 3.58)], low level of SES [2.21 (1.34 to 3.66)], and no previous measurement of HbA1c [12.45 (1.54 to 100.34)] were independently associated with depression. 


\section{Discussion}

This study showed that both anxiety and depression are common in people with T2D atending out-patients clinics in Guinea. The prevalence of depression and anxiety in the present study is higher than that observed previously in Caucasian type 2 diabetic populations [12,13]. However, a recent large cross-sectional multinational study did not find an association between diabetes and the prevalence of depressive symptoms in Africa, in contrast to other continents [14].

Other studies reported a higher prevalence of depression for diabetes in developing countries with results similar to our results in Pakistan $57.9 \%$ had anxiety and $43.5 \%$ had depression [15]. In a recent review, the percentage of people with depression among those with diabetes was $45.9 \%$ in South Africa and between 15 and 30\% in Nigeria [8]. This high prevalence of anxiety and depression in LMICs such as Guinea could be explained by gender inequality, social insecurity, low educational levels and poverty [16].

In the present study, we observed that poor glucose control was independently associated with both anxiety and depression in men. Some previous reports have shown a positive association between HbA1c levels, fasting blood glucose and the level of anxiety $[4,6,17]$. Depressive mood has been also associated with glucose levels in T2D [18]. In a recent study in Netherlands, several individual depressive symptoms were related to higher HbA1c in outpatients with T2D and these associations persisted over time [19]. Underlying mechanisms proposed to explain the increase in glycaemia are enhanced inflammation [20], insulin resistance [21], alterations in insulin secretion [22] and activation of the hypothalamicpituitary-adrenal axis [23]. Furthermore, depression and anxiety are also linked with poorer behavioral management of diabetes and glycemic control [24].

The use of insulin therapy was independently associated with the symptoms of depression. This is in agreement with previous reports [25,26]. Insulin therapy could be associated with negative beliefs about the future and the risk of death for the patient. However, the need for insulin therapy often indicates a more severe stage of the disease, which is characterized by age, poorer glycaemic control, and a higher rate of complications. Nevertheless, in our study, this association persisted after adjusting for age and HbAlc, suggesting that the perceptions surround insulin therapy itself, irrespective of the metabolic context, could favour the development of depressive symptoms. Only a prospective study with a longitudinal follow-up could adequately test this hypothesis.

The lack of previous measurement of HbA1c was independently associated with the presence of depression in women. A number of studies showed that depression is associated 
with poor perceived control of diabetes and poor self-care behaviors [27,28]. In addition, it may be speculated that previous measurement of $\mathrm{HbAlc}$ might be an indirect indicator of the patient's participation in a structured diabetes medical programme, which may have contribute to giving more reassurance to the patient, thereby explaining why these patients were less depressed. The lack of information on glycaemia status might also be potentially worrying to the patient. In addition, depression may prevent efforts dedicated to health, resulting in a lower probability of having an $\mathrm{HbA1c}$ measurement. Nevertheless, reverse causality, by which poor glycaemic control may induce greater psychological distress, cannot be excluded. It was observed that age was independently associated with symptoms of depression whereas duration of diabetes was not an independent risk factor after accounting for age. Findings for the relationship between age and depression in diabetes have been conflicting, with some studies reporting age as a risk factor for depression [15,29] whereas in other studies, younger age was related to depressive symptoms [30].

Our study provides new findings concerning the relationship between socioenvironmental factors and the presence of anxiety/depression in people with T2D in a developing African country. Our results for women showed that those of low SES were twice as likely to be depressed compared with of high SES. This is in agreement with other studies showing that the risk of depression is higher for diabetic patients with lower SES [29,31]. In contrast, however a higher SES was independently found to be associated with the symptoms of anxiety. Unemployment is also a consistent risk factor for psychological disorders, suggesting the importance to taking into consideration the presence of depression among patients with diabetes who are unemployed or who have less education, which is common in Africa [32]. It has been shown that depression is more commonly seen among those with a low family income, non-professional/administrative employment, not current employment and so are dependent, and those living alone and with less social support [29]. Indeed, it has long been recognized that individuals with lower SES suffer a disproportionate share of the burden and consequences of numerous diseases than those with higher SES [33].

It was also revealed that an urban area of residence was independently associated with symptoms of both anxiety and depression in women, a relationship that remains controversial in the developing countries. A study in Pakistan showed a greater prevalence of mental disorders in urban areas than in rural areas [34]. In contrast, no significant association between depression comorbidity and place of residence was found in a study from Nigeria [35]. 
Our present study has several intrinsic limitations. First, as symptoms of depression

2 and anxiety were only measured at one time point, this study cannot directly evaluate the long-term impact of diabetes on the incidence of anxiety /depression. Thus the observational nature of the study allows no conclusions to be drawn on the causality of the link between depression and poor glycaemic control. Second, the study population was not randomly sampled, which limits attempts to generalize the results to all populations with T2D in Guinea. Third, the HADS-D score predominantly reflects melancholic depressive symptoms over the past week. Thus, levels of lifetime depression and the proportion of subjects with atypical depressive symptoms might have been underestimated in our cohort. Also, the study may have slightly underestimated the prevalence of anxiety and depression because patients who had lost a family member and/or lost their job in the month preceding the study were excluded. Finally, it was not possible to adjust for risk factors such as a previous or family history of depression, childhood experiences, life experiences and sickle cell disease. The prevalence of the latter is high in Guinea, and its presence is known to affect measurements of $\mathrm{HbA1c}[36]$.

Our findings show that people with T2D in Sub-Saharan Africa are at risk of anxiety and depression, just as reported in high-income countries [37]. The high prevalence of anxiety and depression in Guinea is an important additional public-health burden, as the country faces an alarming increase in the prevalence of T2D in Africa [38].

These findings also suggest that the healthcare infrastructure, which has traditionally focused on infectious diseases in Guinea, needs to evolve to take better account of the psychological burden associated with diabetes, particularly in urban areas. The screening and monitoring of psychological disorders in people with diabetes are still neglected in Africa, and the treatment of diabetes-related depression is rare in these countries, too [39,40]. Medico-economic studies have shown that the coexistence of depression and diabetes is associated with greater healthcare services and medical costs [4].

In conclusion, our results show that both anxiety and depression are common in people with T2D living in Guinea, irrespective of overweight/obesity status. Poor control of glycaemia, residence in an urban area, the absence of previous measurement of HbA1c and use of insulin therapy appear to be risk factors for depression in this population. These findings suggest that depression in T2D patients in Africa needs to be screened for and taken into consideration in their medical care. 


\section{Competing interests}

2 No potential conflict of interest relevant to this article was reported.

3

\section{Acknowledgment}

5 This project is supported by a grant from the BRIDGES International Diabetes Federation, a

6 project of the International Diabetes Federation, supported by an educational grant from Eli

$7 \quad$ Lilly and Company.

8 We thank the French Society of Diabetes (SFD) for the award to Dr. Alioune Camara in 2009

9 We thank warmly the health professionals who contributed to the recruitment and monitoring 10 of patients, and those who participated in the study. 


\section{References}

[1] Maher D, Smeeth L, Sekajugo J. Health transition in Africa: practical policy proposals for primary care. Bull World Health Organ 2010;88:943-8.

[2] Baldé NM, Diallo I, Baldé MD, Barry IS, Kaba L, Diallo MM, et al. Diabetes and impaired fasting glucose in rural and urban populations in Futa Jallon (Guinea): prevalence and associated risk factors. Diabetes Metab 2007;33:114-20.

[3] Van Dooren FEP, Nefs G, Schram MT, Verhey FRJ, Denollet J, Pouwer F. Depression and Risk of Mortality in People with Diabetes Mellitus: A Systematic Review and Meta-Analysis. PLoS ONE 2013;8: e57058.

[4] Egede LE, Ellis C. Diabetes and depression: Global perspectives. Diabetes Res Clin Pract 2010;87:302-12.

[5] Gonzalez JS, Peyrot M, McCarl LA, Collins EM, Serpa L, Mimiaga MJ, et al. Depression and Diabetes Treatment Nonadherence: A Meta-Analysis. Diabetes Care 2008;31:2398-403.

[6] Pouwer F. Should we screen for emotional distress in type 2 diabetes mellitus? Nat Rev Endocrinol 2009;5:665-71.

[7] Li C, Ford ES, Zhao G, Balluz LS, Berry JT, Mokdad AH. Undertreatment of Mental Health Problems in Adults With Diagnosed Diabetes and Serious Psychological Distress The Behavioral Risk Factor Surveillance System, 2007. Diabetes Care 2010;33:1061-4.

[8] Mendenhall E, Norris SA, Shidhaye R, Prabhakaran D. Depression and type 2 diabetes in low- and middle-income countries: A systematic review. Diabetes Res Clin Pract 2014;103:276-85.

[9] Zigmond AS, Snaith RP. The hospital anxiety and depression scale. Acta Psychiatr Scand 1983;67:361-70.

[10] Lepine JP, Godchau M, Brun P. Anxiety and depression in inpatients. Lancet $1985 ; 2: 1425-6$.

[11] Bjelland I, Dahl AA, Haug TT, Neckelmann D. The validity of the Hospital Anxiety and Depression Scale. An updated literature review. J Psychosom Res 2002;52:69-7.

[12] Anderson RJ, Freedland KE, Clouse RE, Lustman PJ. The Prevalence of Comorbid Depression in Adults With Diabetes A meta-analysis. Diabetes Care 2001;24:1069-78.

[13] Collins MM, Corcoran P, Perry IJ. Anxiety and depression symptoms in patients with diabetes. Diabet Med 2009;26:153-61. 
[14] Mommersteeg PMC, Herr R, Pouwer F, Holt RIG, Loerbroks A. The association between diabetes and an episode of depressive symptoms in the 2002 World Health Survey: an analysis of 231,797 individuals from 47 countries. Diabet Med J Br Diabet Assoc 2013;30:e208-214.

[15] Khuwaja AK, Lalani S, Dhanani R, Azam IS, Rafique G, White F. Anxiety and depression among outpatients with type 2 diabetes: A multi-centre study of prevalence and associated factors. Diabetol Metab Syndr 2010;2:72.

[16] Stein DJ, Gureje O. Depression and anxiety in the developing world: is it time to medicalise the suffering? The Lancet 2004;364:233-4.

[17] Lustman PJ, Clouse RE. Depression in diabetic patients: the relationship between mood and glycemic control. J Diabetes Complications 2005;19:113-22.

[18] Engum A, Mykletun A, Midthjell K, Holen A, Dahl AA. Depression and Diabetes A large population-based study of sociodemographic, lifestyle, and clinical factors associated with depression in type 1 and type 2 diabetes. Diabetes Care 2005;28:1904-9.

[19] Bot M, Pouwer F, de Jonge P, Tack CJ, Geelhoed-Duijvestijn PHLM, Snoek FJ. Differential associations between depressive symptoms and glycaemic control in outpatients with diabetes. Diabet Med 2013;30:e115-e122.

[20] Doyle TA, de Groot M, Harris T, Schwartz F, Strotmeyer ES, Johnson KC, et al. Diabetes, depressive symptoms, and inflammation in older adults: results from the health, aging, and body composition study. J Psychosom Res 2013;75:419-24.

[21] Silva N, Atlantis E, Ismail K. A review of the association between depression and insulin resistance: pitfalls of secondary analyses or a promising new approach to prevention of type 2 diabetes? Curr Psychiatry Rep 2012;14:8-14.

[22] Bot M, Pouwer F, De Jonge P, Nolan JJ, Mari A, Højlund K, et al. Depressive symptoms, insulin sensitivity and insulin secretion in the RISC cohort study. Diabetes Metab 2013;39:42-9.

[23] Penninx BW, Milaneschi Y, Lamers F, Vogelzangs N. Understanding the somatic consequences of depression: biological mechanisms and the role of depression symptom profile. BMC Med 2013;11:129. 
[24] Kendzor DE, Chen M, Reininger BM, Businelle MS, Stewart DW, Fisher-Hoch SP, et al. The association of depression and anxiety with glycemic control among Mexican Americans with diabetes living near the U.S.-Mexico border. BMC Public Health 2014;14:176.

[25] Papelbaum M, Moreira RO, Coutinho W, Kupfer R, Zagury L, Freitas S, et al. Depression, glycemic control and type 2 diabetes. Diabetol Metab Syndr 2011;3:26.

[26] Joseph N, Unnikrishnan B, Raghavendra Babu YP, Kotian MS, Nelliyanil M. Proportion of depression and its determinants among type 2 diabetes mellitus patients in various tertiary care hospitals in Mangalore city of South India. Indian J Endocrinol Metab 2013;17:681-8.

[27] Egede LE, Osborn CY. Role of Motivation in the Relationship Between Depression, Self-care, and Glycemic Control in Adults With Type 2 Diabetes. Diabetes Educ 2010;36:276-83.

[28] Gonzalez JS, Safren SA, Cagliero E, Wexler DJ, Delahanty L, Wittenberg E, et al. Depression, Self-Care, and Medication Adherence in Type 2 Diabetes Relationships across the full range of symptom severity. Diabetes Care 2007;30:2222-7.

[29] Leone T, Coast E, Narayanan S, Aikins A de G. Diabetes and depression comorbidity and socio-economic status in low and middle income countries (LMICs): a mapping of the evidence. Glob Health 2012;8:39.

[30] Egede LE, Zheng D. Independent Factors Associated With Major Depressive Disorder in a National Sample of Individuals With Diabetes. Diabetes Care 2003;26(1):104-11.

[31] Everson SA, Maty SC, Lynch JW, Kaplan GA. Epidemiologic evidence for the relation between socioeconomic status and depression, obesity, and diabetes. J Psychosom Res 2002;53:891-5.

[32] Patel V, Kleinman A. Poverty and common mental disorders in developing countries. Bull World Health Organ 2003;81:609-15.

[33] Adler NE, Newman K. Socioeconomic Disparities In Health: Pathways And Policies. Health Aff (Millwood) 2002;21:60-76.

[34] Rahim SI, Cederblad M. Epidemiology of mental disorders in young adults of a newly urbanized area in Khartoum, Sudan. Br J Psychiatry J Ment Sci 1989;155:44-7.

[35] Agbir T, Audu M, Adebowale T, Goar S. Depression among medical outpatients with diabetes: A cross-sectional study at Jos University Teaching Hospital, Jos, Nigeria. Ann Afr Med 2010;9:5. 
1 [36] Ama V, Kengne AP, Nansseu NJR, Nouthe B, Sobngwi E. Would sickle cell trait

2

3

4

5

6

7

8

9

10

11

12 influence the metabolic control in sub-Saharan individuals with type 2 diabetes?: Sickle cell trait and diabetes in Africa. Diabet Med 2012;29:e334-e337.

[37] Petrak F, Herpertz S, Albus C, Hirsch A, Kulzer B, Kruse J. Psychosocial factors and diabetes mellitus: evidence-based treatment guidelines. Curr Diabetes Rev 2005;1:255-70.

[38] Mbanya JCN, Motala AA, Sobngwi E, Assah FK, Enoru ST. Diabetes in sub-Saharan Africa. The Lancet 2010;375:2254-66.

[39] Crabb J, Stewart RC, Kokota D, Masson N, Chabunya S, Krishnadas R. Attitudes towards mental illness in Malawi: a cross-sectional survey. BMC Public Health 2012;12:541.

[40] Barke A, Nyarko S, Klecha D. The stigma of mental illness in Southern Ghana: attitudes of the urban population and patients' views. Soc Psychiatry Psychiatr Epidemiol 2011;46:1191-202. 
3

\begin{tabular}{|c|c|c|c|c|c|c|}
\hline \multirow[b]{2}{*}{ Age (years) } & & \multicolumn{2}{|c|}{ Men $(n=183)$} & \multicolumn{2}{|c|}{ Women $(n=308)$} & \multirow{2}{*}{$\begin{array}{c}\text { P value } \\
0.001\end{array}$} \\
\hline & & 59.8 & $( \pm 9.7)$ & 56.7 & $( \pm 10.3)$ & \\
\hline Urban zone of residence & & 112 & $(61.2)$ & 194 & $(63.0)$ & 0.69 \\
\hline Low level of education ( $<7$ years) & & 67 & $(36.6)$ & 176 & $(57.1)$ & $<0.001$ \\
\hline Unemployed & & 51 & $(27.9)$ & 174 & $(56.5)$ & $<0.001$ \\
\hline Duration of diabetes (years) & & 8.2 & $( \pm 6.5)$ & 7.5 & $( \pm 3.3)$ & 0.23 \\
\hline Insulin therapy use & & 43 & $(23.5)$ & 100 & $(32.5)$ & 0.03 \\
\hline Known hypertension & & 150 & $(82.0)$ & 269 & $(87.3)$ & 0.10 \\
\hline $\operatorname{BMI}\left(\mathrm{kg} / \mathrm{m}^{2}\right)$ & & 23.6 & $( \pm 3.6)$ & 26.5 & $( \pm 4.8)$ & $<0.001$ \\
\hline Current smoker & & 11 & $(6.0)$ & 0 & $(0.0)$ & $<0.001 *$ \\
\hline Alcohol consumption & & 34 & $(18.6)$ & 5 & $(1.6)$ & $<0.001$ \\
\hline Previous measurement of $\mathrm{HbA} 1 \mathrm{c}$ & & 16 & $(8.7)$ & 17 & $(5.5)$ & 0.17 \\
\hline \multirow[t]{3}{*}{ HbA1c control } & $<7 \%$ & 34 & $(18.6)$ & 43 & $(14.0)$ & 0.02 \\
\hline & $7-8.9 \%$ & 71 & $(38.8)$ & 94 & $(30.5)$ & \\
\hline & $\geq 9 \%$ & 78 & $(42.6)$ & 171 & $(55.5)$ & \\
\hline $\mathrm{HbA} 1 \mathrm{c}(\%)$ & & 9.2 & $(2.5)$ & 9.7 & $(2.4)$ & 0.03 \\
\hline HAD-A & & 7.2 & $( \pm 2.8)$ & 9.2 & $( \pm 3.2)$ & $<0.001$ \\
\hline HAD-D & & 5.6 & $( \pm 3.3)$ & 6.8 & $( \pm 3.3)$ & $<0.001$ \\
\hline
\end{tabular}

Data are presented as n(\%), means \pm SD; * by Fischer test; HADS-A/D: Hospital Anxiety and

Depression Scale for anxiety/depression. 
Table 2

Prevalence according to severity of symptoms of anxiety and depression as measured by Hospital Anxiety and Depression Scale (HADS) in 491 diabetic outpatients in Guinea by gender.

\begin{tabular}{|c|c|c|c|c|c|c|c|c|}
\hline \multirow[b]{2}{*}{ Scale } & \multicolumn{4}{|c|}{ Anxiety, $n(\%)$} & \multicolumn{4}{|c|}{ Depression, $n(\%)$} \\
\hline & Overall & $95 \% \mathrm{CI}$ & Women & Men & Overall & $95 \% \mathrm{CI}$ & Women & Men \\
\hline Normal (0-7) & $203(41.3)$ & $36.9-45.6$ & $99(32.1)$ & $104(56.8)$ & $322(65.6)$ & $61.4-69.8$ & $187(60.7)$ & $135(73.8)$ \\
\hline Mild disorder (8-10) & $153(31.2)$ & $27.1-35.3$ & $98(31.8)$ & $55(30.1)$ & $113(23.0)$ & $19.3-26.7$ & $78(25.3)$ & $35(19.1)$ \\
\hline Marked disorder (11-21) & $135(27.5)$ & $23.5-31.4$ & $111(36.1)$ & $24(13.1)$ & $56(11.4)$ & $8.6-14.2$ & $43(14.0)$ & $13(7.1)$ \\
\hline
\end{tabular}


Table 3

Factors associated with symptoms of anxiety (Score HADS-A $\geq 8$ ) in outpatients with Type 2 diabetes in Guinea.

\begin{tabular}{|c|c|c|c|c|c|c|c|c|c|}
\hline \multirow[b]{4}{*}{ Characteristics } & & \multicolumn{8}{|c|}{ Anxiety (Scale HADS-A $\geq 8-21$ vs. 0-7) } \\
\hline & & \multicolumn{4}{|c|}{ Men $(n=183)$} & \multicolumn{4}{|c|}{ Women $(n=308)$} \\
\hline & & \multirow{2}{*}{$\begin{array}{l}\text { OR crude } \\
(95 \% \mathrm{CI})\end{array}$} & \multicolumn{3}{|c|}{ OR adjusted } & \multirow{2}{*}{$\begin{array}{l}\text { OR crude } \\
(95 \% \mathrm{CI})\end{array}$} & \multicolumn{3}{|c|}{ OR adjusted } \\
\hline & & & $P$ value & $(95 \% \mathrm{CI})$ & $P$ value & & $\mathrm{P}$ value & $(95 \% \mathrm{CI})$ & $\mathrm{P}$ value \\
\hline Ages (years) & & $0.98(0.96-1.02)$ & 0.34 & & & $0.98(0.96-1.00)$ & 0.09 & $0.98(0.96-1.00)$ & 0.06 \\
\hline Zone of Residence & Urban vs. Rural & $1.17(0.64-2.13)$ & 0.61 & & & $2.98(1.81-4.89)$ & $<0.001$ & $2.98(1.81-4.89)$ & $<0.001$ \\
\hline Married & Yes vs. No & $0.75(0.18-3.09)$ & 0.69 & & & $1.09(0.66-1.79)$ & 0.74 & & \\
\hline Socio-Economic Status & Low vs. High & $0.22(0.06-0.77)$ & 0.02 & $0.19(0.05-0.70)$ & 0.01 & $0.91(0.56-1.47)$ & 0.70 & & \\
\hline Insulin therapy use & Yes vs. No & $1.06(0.53-2.10)$ & 0.88 & & & $1.43(0.85-2.42)$ & 0.18 & $1.17(0.67-2.05)$ & 0.58 \\
\hline Duration of diabetes (years) & & $0.99(0.94-1.03)$ & 0.57 & & & $1.05(1.01-1.11)$ & 0.03 & $1.05(0.99-1.10)$ & 0.05 \\
\hline Previous measurement of $\mathrm{HbA} 1 \mathrm{c}$ & No vs. Yes & $1.29(0.45-3.72)$ & 0.63 & & & $1.51(0.56-4.10)$ & 0.41 & & \\
\hline \multirow[t]{2}{*}{ HbA1c (versus <7.0\%) } & 7.0 to $8.9 \%$ & $2.55(1.05-6.23)$ & 0.04 & $2.80(1.13-6.93)$ & 0.02 & $1.09(0.51-2.33)$ & 0.82 & & \\
\hline & $\geq 9.0 \%$ & $2.38(1.00-5.75)$ & 0.04 & $2.61(1.07-6.39)$ & $\mathbf{0 . 0 3}$ & $1.19(0.59-2.41)$ & 0.62 & & \\
\hline Known HTA & Yes vs. No & $0.57(0.27-1.22)$ & 0.14 & $0.55(0.25-1.22)$ & 0.14 & $0.60(0.27-1.31)$ & 0.20 & & \\
\hline BMI $\left(\mathrm{kg} / \mathrm{m}^{2}\right)$ & & $0.97(0.89-1.05)$ & 0.49 & & & $1.00(0.95-1.05)$ & 0.91 & & \\
\hline Current smoker & Yes vs. No & $1.63(0.48-5.54)$ & 0.43 & & & - & - & & \\
\hline Alcohol consumption & Yes vs. No & $1.30(0.61-2.77)$ & 0.49 & & & $0.71(0.12-4.29)$ & 0.70 & & \\
\hline
\end{tabular}




\section{Table 4}

Factors associated with symptoms of depression (Scale HADS-D $\geq 8$ ) in outpatients with Type 2 diabetes in Guinea.

\begin{tabular}{|c|c|c|c|c|c|c|c|c|c|}
\hline \multirow[b]{4}{*}{ Characteristics } & & \multicolumn{8}{|c|}{ Depression (Scale HADS-D $\geq 8-21$ vs. $0-7$ ) } \\
\hline & & \multicolumn{4}{|c|}{ Men $(n=183)$} & \multicolumn{4}{|c|}{ Women $(n=308)$} \\
\hline & & \multirow{2}{*}{$\begin{array}{l}\text { OR crude } \\
(95 \% \text { IC) }\end{array}$} & \multicolumn{3}{|c|}{ OR adjusted } & \multirow{2}{*}{$\begin{array}{l}\text { OR crude } \\
(95 \% \text { IC) }\end{array}$} & \multicolumn{3}{|c|}{ OR adjusted } \\
\hline & & & $\mathrm{P}$ value & $(95 \%$ IC) & $P$ value & & $\mathrm{P}$ value & $(95 \% \mathrm{IC})$ & $P$ value \\
\hline Ages (years) & & $1.03(0.99-1.07)$ & 0.10 & $1.04(0.99-1.08)$ & 0.07 & $1.04(1.01-1.06)$ & 0.003 & $1.03(1.01-1.06)$ & 0.02 \\
\hline Zone of Residence & Urban vs. Rural & $0.96(0.49-1.88)$ & 0.90 & & & $1.69(1.04-2.75)$ & 0.03 & $2.13(1.27-3.58)$ & 0.004 \\
\hline Married & Yes vs. No & $0.57(0.13-2.51)$ & 0.46 & & & $0.81(0.50-1.30)$ & 0.38 & & \\
\hline Socio-Economic Status & Low vs. High & $1.34(0.48-3.75)$ & 0.58 & & & $2.61(1.63-4.18)$ & $<0.001$ & $2.21(1.34-3.66)$ & 0.002 \\
\hline Insulin therapy use & Yes vs. No & $3.03(1.46-6.27)$ & 0.002 & $2.28(1.05-4.92)$ & 0.04 & $1.42(0.87-2.31)$ & 0.15 & $1.27(0.75-2.16)$ & 0.37 \\
\hline Duration of diabetes (years) & & $1.03(0.97-1.08)$ & 0.26 & & & $0.99(0.95-1.04)$ & 0.80 & & \\
\hline Previous measurement of $\mathrm{HbAlc}$ & No vs. Yes & $5.87(0.75-45.73)$ & 0.09 & $6.65(0.81-54.94)$ & 0.08 & $11.22(1.47-85.75)$ & 0.02 & $12.45(1.54-100.34)$ & 0.02 \\
\hline \multirow[t]{2}{*}{ HbA1c (versus <7.0\%) } & 7.0 to $8.9 \%$ & $3.51(0.96-12.88)$ & 0.06 & $2.99(0.80-11.11)$ & 0.10 & $1.34(0.63-2.87)$ & 0.44 & & \\
\hline & $\geq 9.0 \%$ & $5.47(1.53-19.55)$ & 0.008 & $3.85(1.02-14.48)$ & 0.04 & $1.44(0.71-2.91)$ & 0.32 & & \\
\hline Known HTA & Yes vs. No & $0.78(0.34-1.78)$ & 0.56 & & & $0.64(0.33-1.26)$ & 0.19 & $0.57(0.27-1.18)$ & 0.19 \\
\hline BMI $\left(\mathrm{kg} / \mathrm{m}^{2}\right)$ & & $0.91(0.83-1.00)$ & 0.05 & $0.92(0.83-1.02)$ & 0.12 & $0.94(0.90-0.99)$ & 0.02 & $0.97(0.92-1.92)$ & 0.29 \\
\hline Current smoker & Yes vs. No & $0.61(0.13-2.92)$ & 0.53 & & & - & - & & \\
\hline Alcohol consumption & Yes vs. No & $1.07(0.46-2.49)$ & 0.88 & & & $0.38(0.04-3.45)$ & 0.39 & & \\
\hline
\end{tabular}

HADS-D: Hospital Anxiety and Depression Scale for depression.; 95\% CI: 95\% confidence interval 